\title{
Pollination efficiency on Ipomoea bahiensis (Convolvulaceae): morphological and behavioural aspects of floral visitors
}

\author{
Laene S. Araujo',2 (1D https://orcid.org/0000-0002-8833-4202 \\ Anderson M. Medina ${ }^{3}$ (1) https://orcid.org/0000-0002-8800-6444 \\ Miriam Gimenes² (1D https://orcid.org/0000-0002-6501-6623
}

\begin{abstract}
1. Postgraduate Program in in Ecology and Evolution, Universidade Estadual de Feira de Santana.
2. Universidade Estadual de Feira de Santana (UEFS), Rodovia BR-116, Km 3, 44031-460, Campus Universitário, Feira de Santana, BA, Brazil. (laenesilvaaraujo@yahoo.com.br) 3. Postgraduate Program in Ecology and Evolution, Universidade Federal de Goiás, Brasil.
\end{abstract}

Received 4 October 2017

Accepted 9 April 2018

Published 11 June 2018

DOI 10.1590/1678-4766e2018012

ABSTRACT. Pollination depends on morphological and behavioural adjustments between visitors and plants. Some plant species as Ipomoea bahiensis (Convolvulaceae) provide nectar and pollen to visitors and occur in anthropic areas, therefore becoming an important source of resources for the maintenance of native pollinating insects. However, what is the efficiency of each floral visitor species for the pollination of this plant species? What morphological and behavioural characteristics determine the pollinators? In this regard, this study evaluated the I. bahiensis flower and visitor morphology in a semi-arid area and the foraging behaviour of these floral visitors. Also, the efficiency rate of potential pollinators was quantified. Bees and butterflies visited the flowers of I. bahiensis, but the bees Melitoma spp., Apis mellifera (Linnaeus, 1758), and Pseudaugochlora pandora (Smith, 1853) were the most frequent visitors. These species presented medium-sized and compatible with the floral tube width. In addition to the size, these bees presented behaviour that favoured the contact with the reproductive structures of the flower, as evidenced by the efficiency test of the flower visits. Although butterflies often collect nectar from the flowers, they do not present characteristics that could result in pollination. Hence, medium-sized bees played the role of efficient pollinator of $I$. bahiensis.

KEYWORDS. Apis mellifera, Melitoma, Pseudaugochlora pandora, Bee-flower interaction.

Pollination depends on the adjustment between the traits of flowers and their visitors. Morphology and behaviour are key traits to mediate contact of visitors with the flower anthers and stigma during the collection of resources, therefore essential aspects on pollination efficiency (Machado \& Sazima, 1987; Parra-Tabla \& Bullock, 2003; PINTO-TORRES \& KoPTUR, 2009).

Some plant families have flowers with important traits, such as odour, shape, size and colour, that ensures specialized pollination and increase pollination efficiency. For example, pollinators for flowers with tube lengths that match proboscis length on a plant-pollinator mutualism in the interaction between a long-tongued fly [Prosoeca ganglbaueri Lichtwardt, 1910 (Nemestrinidae)] and its primary floral food plant [Zaluzianskya microsiphon, (O. Kuntze) K. Schum. (Scrophulariaceae)] (ANDERSON \& JoHnson, 2008). In general, tubular flowers are expected to restrict entry into the floral tube only to visitors with adequate morphology. This trait is present on morning glory flowers (Convolvulaceae), therefore, it is expected that species of this family, including those of the genus Ipomoea, present a relation between the size of the floral tube and the size of the visitor resulting in the contact with reproductive structures, as a means of ensuring pollination (PAZ et al., 2013).
Another factor affecting pollination efficiency is related to the temporal adjustment between visitors and flowers. Some plants, especially Ipomoea spp. (Convolvulaceae) with short-lived flowers and diurnal opening, early in the morning, are more visited by diurnal bees (MAIMONI-Rodella \& Yanagizawa, 2007; PAz et al., 2013). However, some species with diurnal flower opening are also pollinated by hummingbirds and butterflies (MACHADO \& SAZIMA, 1987; MARAIS \& RAUSHER, 2010) and species with nocturnal flower opening are usually pollinated by moth (MURCIA, 1990; PAZ et al., 2013). Pollination in Ipomoea species relates this group to a variety of possible pollinators, however, pollination efficiency of these visitors needs to be tested.

Among the floral visitors of diurnal species of Ipomoea, some bee species are generally associated with its flowers (Wcislo \& Cane, 1996; Martins, 2002), such as the oligolectic bees of the genus Melitoma that are important pollinators of this plant genus (TERADA et al., 2005; M.-Rodella \& Yanagizawa, 2007; Pick \& Schlindwein, 2011, Paz \& Pigozzo, 2013; Paz et al., 2013). Oligolectic bees are generally more frequent and able to access floral resources easier than polylectic bees on flowers with restrictive morphology (SCHLINDWEIN, 
2004). However, among the floral visitors of a plant species may occur specialist and generalist species and both can act as potential pollinators, but differing in quality of service provided (NE'EMAN et al., 2010).

Species of Ipomoea are commonly found on anthropogenic areas, so they can be an important source of pollen and nectar for the maintenance of populations of floral visitors of recognized importance in the literature (MAIMONIRodella \& Yanagizawa, 2007; Paz et al., 2013). In this regard, this study aims to identify the most efficient pollinators of Ipomoea bahiensis Willd. Ex Roem. \& Schult through analysis of the morphological and behavioural characteristics of the floral visitors. Particularly, the pollination efficiency is expected to be related to visitors with compatible size with the floral tube dimensions of $I$. bahiensis and behaviour that allows contact with reproductive structures.

\section{MATERIAL AND METHODS}

The study was carried out at the Campus of Universidade Estadual de Feira de Santana (Bahia, Brazil) $\left(12^{\circ} 11^{\prime} \mathrm{S}, 38^{\circ} 58^{\prime} \mathrm{W}\right)$ that encompass a total area of approximately $1.2 \mathrm{~km}^{2}$; the vegetation is predominantly herbaceous-shrub Caatinga, but is now covered by anthropized vegetation with non-native and invasive plants (SANTANA \& SANTOS, 1999). The regional climate is classified as BSh or semiarid (KöPPEN \& GEIGER, 1928).

Ipomoea bahiensis is a ruderal and climbing plant species, with sympetalous corolla, funnel-shaped. The flowers are showy, with colour ranging from light to dark purple, the tube has more intense colour than the rest of the corolla and they are arranged in an inflorescence with 5-10 bisexual flowers. The species presents the reproductive organs inserted inside the floral tube, organised in the central region of this tube, being the five stamens located around the stigma (PACHeCO-FILHO et al., 2011).

The fieldwork was carried out between July and October 2014, which were the months with the greatest flowering of I. bahiensis in the study area. The data collection were made in four sample plots $(20 \times 20 \mathrm{~m}$ each) at least $200 \mathrm{~m}$ apart from each other.

Reproductive biology experiments were carried out during July 2014. The treatments on the experiment were: manual cross-pollination/geitonogamy (transfer of pollen among different flowers of a single individual of $I$. bahiensis), manual cross-pollination/xenogamy (transfer of pollen among flowers of different individuals), spontaneous self-pollination (flowers bagged without any intervention), manual self-pollination (transfer of anther pollen to the stigma of the same flower), apomixis/agamospermy (flowers emasculated and bagged to observe if fruit formation occur without fertilization), and control (flowers exposed to the action of visitors). For the tests, 40 flowers from the four sample plots studied (bagged before floral opening) were used for each treatment, in a total of 240 flowers.

In order to compare the different pollination treatments mentioned above, a generalized linear model with binomial distribution was constructed (ZUUR et al., 2009), using the treatment as a predictor variable and fruit formation (binary) as a response variable. Afterwards, a planned comparisons was performed comparing pollination treatments with the control using the glht function of the multcomp package (Hothorn et al., 2008). All analysis were performed on R environment unless stated otherwise (R CORE TEAM, 2017)

Morphology of the flowers. In order to evaluate if the floral visitor sizes matches with flower traits, anther and stigma lengths, corolla length and diameter, and width of the internal area of the floral tube available for passage of visitors through the flowers to the nectary $(n=20)$ were measured using a digital calliper. The flowers were collected in the four sample plots selected. The voucher plant specimens of this study are deposited at the Universidade Estadual de Feira de Santana Herbarium (HUEFS-212109).

Morphology and behaviour of floral visitors. Morphological and behavioural aspects served as a baseline to determine the potential pollinators. First, the size of floral visitors was measured to compare with the diameter of the floral tube. These measures of body length (from mid-ocellus to apex of the abdomen) and inter-tegular width (distance between the bases of the tegulas) were made using a digital calliper. The size classification for floral visitors was modified from the categories of RouBIK (1989) and FrANKIE et al. (1983), in which visitors were classified as large (length $>14.0$ $\mathrm{mm}$, width $>4.0 \mathrm{~mm}$ ), robust medium (length: 10.0 to 14.0 $\mathrm{mm}$, width: 4.0 to $6.0 \mathrm{~mm}$ ), intermediate medium (length: 10.0 to $14.0 \mathrm{~mm}$; width: 3.0 to $4.0 \mathrm{~mm}$ ), small medium (length: 7.0 to $10.0 \mathrm{~mm}$; width: 2.0 to $4.0 \mathrm{~mm}$ ), and small (length: $<7.0 \mathrm{~mm}$, width: $<2.0 \mathrm{~mm}$ ).

The observations of visitor behaviour were made from 04:00 to 15:00 h, during two days in July, August, September, and October/2014 and the following was observed: type of resource collected, parts of the body that contacted the reproductive structures of flowers, and visit duration. The floral visitor specimens collected were deposited in the entomological collection Prof Johann Becker at the Museu de Zoologia da Universidade Estadual de Feira de Santana (MZFS).

Pollination efficiency. The experiments to verify the pollination efficiency in I. bahiensis were carried out with floral visitors considered as potential pollinators according to the following criteria: 1) high frequency of visits, 2) body size matching floral tube width, 3) behaviour of touching the reproductive structures of flowers during the collection of resources.

In order to test the pollination efficiency of the most frequent visitors to flowers, preliminary experiments with a visit to flower were carried out, but no fruit formation was verified, therefore this experiment was carried out with three visits to flower. Bagged flowers in bud stage were used in the experiments and were un-bagged after the floral opening, in which only selected visitors were allowed to make three visits per flower. This procedure was performed on 30 flowers for each potential pollinator and the flowers were marked and bagged again to follow the fruit production. 


\section{RESULTS}

In the reproductive biology experiments, only the treatments of geitonogamy and xenogamy were similar to the results obtained in natural conditions (Control) with $60 \%$ of probability of forming fruits, also there was $12.5 \%$ of fruit formation in the manual self-pollination test $\left(\chi^{2}=96.81\right.$, d.f. $=5$, $\mathrm{p}<0.001$ ) (Fig. 1).

According to morphometric data of the flowers, $I$. bahiensis was classified as a large flower, due to the corolla size $(53.02 \pm 7.38 \mathrm{~mm})$. The floral tube was $9.23 \pm 0.99 \mathrm{~mm}$ wide, but the distance between the tube and reproductive structures, through which the visitor could cross to collect the resources, presented a narrow width $(3.51 \pm 0.70 \mathrm{~mm})$. The anthers presented different lengths $(12.32 \pm 1.40 \mathrm{~mm}$, $16.70 \pm 2.49 \mathrm{~mm}, 21.12 \pm 1.86 \mathrm{~mm})$, and the stigma presented length compatible with small and medium anthers (15.02 \pm $1.74 \mathrm{~mm})$.

Ipomoea bahiensis flowers were visited by 28 insect species. The most frequent visitors were bees (70\%): Melitoma spp. [Melitoma segmentaria (Fabricius, 1804), Melitoma sp. 1, Melitoma sp. 2)] (Relative frequency $=25 \%$ ), Apis mellifera Linnaeus, 1758 (23\%), Pseudaugochlora pandora (Smith, 1853) (12\%), and Ancyloscelis apiformes (Fabricius, 1793) (6\%); and butterflies (30\%): Morys compta compta (Butler, 1877) (10\%) and Phoebis sennae marcellina (Cramer, 1777) (8\%). The other floral visitors had a relative frequency lower than 5\% (Tab. I). Among these visitors Melitoma spp., Melitomella murihirta, Trigona spinipes collected pollen and nectar from the flowers, the others visitors collected only nectar.

Medium-sized bees were the visitor species with nearest body size to the size to the floral tube (Fig. 2). The medium-sized bees most similar to the internal size of the tube were: A. mellifera, Melitoma spp., Thygater (Thygater) analis (Lepeletier, 1841) (intermediate-medium), Gaesischia (Gaesischia) cf. similis Urban, 1989, Melipona quadrifasciata anthidioides Lepeletier, 1836, Melitomella murihirta (Cockerell, 1912), Ptilothrix cf. plumata Smith, 1853 (small-medium), however only two bees were abundant (A. mellifera and Melitoma spp.).

Intermediate-medium-sized bees and also smallmedium-sized $P$. pandora collected nectar from the flowers landing on a petal, heading towards the nectary through the tube wall, in a way that they contacted the dorsal part of the body on the reproductive structures of the flowers. On another hand, small bees, such as A. apiformes, also landed on the corolla and headed to the nectary, but always walking on the floral tube wall, both when they arrived and left the tube, contacting the anthers only occasionally. The robustmedium-sized bees were restricted due to the internal size of the floral tube and because of this could not enter the tube.

The behavior of Melitoma spp. while collecting nectar was similar to other intermediate medium-sized bees, resulting in contact of the dorsal part of the body with the reproductive structures of the flower. Melitoma spp. collected pollen by landing on a petals, entered the flower, and positioned themselves on the anthers, scraping them

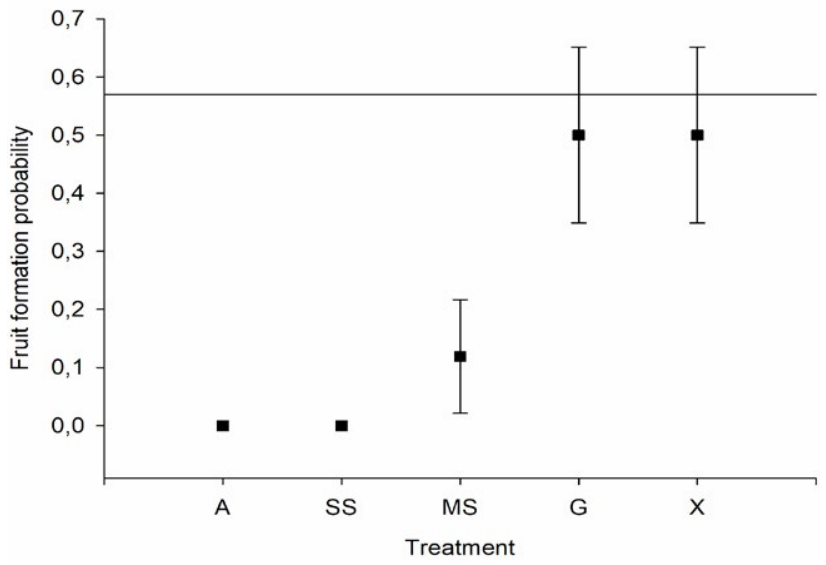

Fig. 1. Comparison between the probabilities of fruit formation in different treatments of reproductive biology test and the control in Ipomoea bahiensis (Convolvulaceae), in Feira de Santana (BA). Control in natural conditions in the horizontal line, points = other treatments: apomixis (A), spontaneous self-pollination (SS), manual self-pollination (MS), geitonogamy (G), and xenogamy $(\mathrm{X})$.

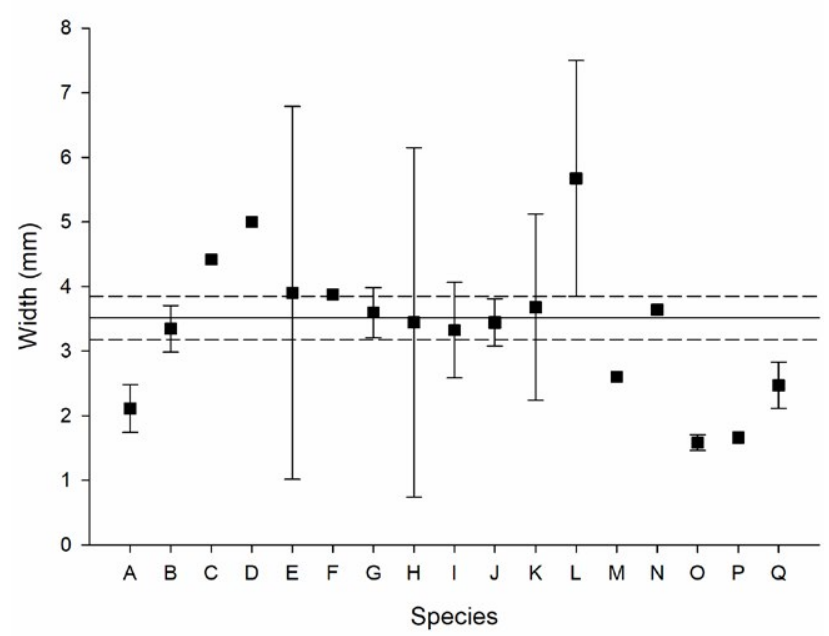

Fig. 2. Relation between the average width of bee species and the width of the internal area of the floral tube of Ipomoea bahiensis. Horizontal dashed lines $=$ confidence interval of the internal area of the floral tube. Points $=$ average visitor size, Bars = confidence interval. Species: (A) Ancyloscelis apiformes; (B) Apis mellifera; (C) Centris (Hemisiela) tarsata; (D) Euglossa (Euglossa) sp.; (E) Gaesischia (Gaesischia) cf. similis; (F) Melipona quadrifasciata; (G) Melitoma segmentaria; (H) Melitoma sp. 1; (I) Melitoma sp. 2; (J) Melitomella murihirta; (K) Ptilithrix cf. plumata; (L) Ptiloglossa sp.; (M) Protomeliturga turnerae; (N) Thygater (Thygater) analis; (O) Trigona spinipes; (P) Augochlora sp.; (Q) Pseudaugochlora pandora

with the hind legs and storing the pollen in the scopa. The bees spun on the anthers to collect pollen, contacting the stigma with the abdomen.

Usually Lepidoptera species inserted the long proboscis in the corolla internal wall until reaching the nectary in order to collect nectar. They oriented themselves through the petal ribs and, with this behaviour, they did not touch the reproductive structures of flowers. $M$. compta compta was the only Lepidoptera that entered until half of floral tube. This butterfly insert the short proboscis in the corolla and to reach the nectary needs to force the entry into the floral tube, contacted the longer anthers, eventually adhering pollen 
to the front of the head. Probably the difference in nectargathering behavior among different species of butterflies can be related to the size of probocides.

The highest fruit production in the pollination efficiency test with three visits was recorded for Melitoma spp., followed by A. mellifera and P. pandora, and the genus Melitoma was considered the most efficient pollinator (Tab. II). Two species ( $M$. compta compta and $A$. apiformes) were disregarded as efficient pollinators due to no fruit formation occurred in the efficiency test with three visits.

\section{DISCUSSION}

Fruit production by I. bahiensis was higher by crosspollination than by self-pollination. Hence, pollen transfers between different flowers, from the same plant (geitonogamy) or from different plants (xenogamy), resulted in a higher fruit production, which gives support for the need of floral visitors for pollination to occur.

In several plant species, the diameter of the floral tube for passage of visitors until the resource is an important morphological trait for the determination of pollinators and their efficiency, restricting the access of visitors with a greater width than the tube. In I. bahiensis flowers, mediumsized bees showed to be potential pollinators (Tab. I), some species being more efficient than others. Among these bees, Melitoma presented a high number of visits, with behaviour and morphology that provided the contact with the reproductive structures of $I$. bahiensis, while collecting pollen and nectar. These bees also showed the highest result

Tab. I. Number of visits (V), floral visitor size (Le - Wi, Length - Width; S, Size; L, large; RM, robust medium; IM, intermediate medium; SM, small medium; small, SS) in Ipomoea bahiensis (Convolvulaceae), Feira de Santana (BA), from July to October 2014. Species marked with an asterisk collected both nectar and pollen while species without asterisk collected only nectar.

\begin{tabular}{|c|c|c|c|}
\hline Species & $\mathrm{V}$ & Le - Wi (mm) & $\mathrm{S}$ \\
\hline \multicolumn{4}{|l|}{ HYMENOPTERA } \\
\hline \multicolumn{4}{|l|}{ Apidae } \\
\hline Ancyloscelis apiformis (Fabricius, 1793) & 226 & $6.60-1.99$ & SS \\
\hline Apis mellifera (Lepeletier, 1836) & 848 & $11.28-3.34$ & IM \\
\hline Centris tarsata Smith, 1874 & 1 & $11.77-4.48$ & RM \\
\hline Euglossa (Euglossa) sp. & 9 & $10.82-5.00$ & $\mathrm{RM}$ \\
\hline Gaesischia (Gaesischia) cf. similis Urban, 1989 & 7 & $9.57-3.66$ & SM \\
\hline Melipona quadrifasciata Lepeletier, 1836 & 1 & $8.90-3.88$ & SM \\
\hline $\begin{array}{l}\text { Melitoma } \text { spp.* [M. segmentaria (Fabricius, 1804), } \\
\text { Melitoma } \text { sp.1, Melitoma } \text { sp.2] }\end{array}$ & 950 & $10.18-3.60$ & IM \\
\hline Melitomella murihirta* (Cockerell, 1912) & 26 & $9.33-3.56$ & SM \\
\hline Ptilothrix cf. plumata Smith, 1853 & 3 & $9.16-3.68$ & SM \\
\hline Ptiloglossa sp. & 26 & $16.32-5.67$ & $\mathrm{~L}$ \\
\hline Protomeliturga turnerae (Ducke, 1907) & 1 & $6.7-2.0$ & SS \\
\hline Thygater analis (Lepeletier, 1841) & 26 & $10.3-3.64$ & IM \\
\hline Trigona spinipes* (Fabricius, 1793) & 16 & $5.82-1.58$ & SS \\
\hline \multicolumn{4}{|l|}{ Halictidae } \\
\hline Augochlora sp. & 8 & $7.18-2.01$ & SM \\
\hline Pseudaugochlora pandora (Smith, 1853) & 461 & $8.65-2.46$ & SM \\
\hline \multicolumn{4}{|l|}{ LEPIDOPTERA } \\
\hline \multicolumn{4}{|l|}{ Pieridae } \\
\hline Phoebis sennae marcellina (Cramer, 1777) & 295 & $18.13-4.01$ & $\mathrm{~L}$ \\
\hline \multicolumn{4}{|l|}{ Hesperiidae } \\
\hline Cymaenes tripunctus theogenis (Capronnier, 1874) & 107 & $14.13-4.53$ & $\mathrm{~L}$ \\
\hline Morys compta compta (Butler, 1877) & 360 & $17.59-4.19$ & $\mathrm{~L}$ \\
\hline Nyctelius nyctelius nyctelius (Latreille, 1824 & 141 & $18.21-4.96$ & $\mathrm{~L}$ \\
\hline Perichares philetes adela (Hewitson, 1867) & 10 & $22.71-5.86$ & $\mathrm{~L}$ \\
\hline Synale hylaspes (Stoll, 1781) & 171 & $17.97-4.54$ & $\mathrm{~L}$ \\
\hline \multicolumn{4}{|l|}{ Sphingidae } \\
\hline Xylophanes indistincta (Closs, 1915) & 12 & $40.42-10.20$ & $\mathrm{~L}$ \\
\hline
\end{tabular}

Tab. II. Pollination efficiency rate of the potentials pollinators of Ipomoea bahiensis (Convolvulaceae), in Feira de Santana, state of Bahia, Brazil.

\begin{tabular}{|c|c|c|c|}
\hline Floral visitor & Flower (n) & Fruit (n) & Success $(\%)$ \\
\hline Melitoma spp. & 30 & 8 & 26.6 \\
\hline Apis mellifera scutellata (Lepeletier, 1836) & 30 & 4 & 13.3 \\
\hline Pseudaugochlora pandora (Smith, 1853) & 30 & 2 & 6.6 \\
\hline Morys compta compta (Butler, 1877) & 30 & 0 & 0.0 \\
\hline Ancyloscelis apiformes & 30 & 0 & 0.0 \\
\hline
\end{tabular}


in the pollination efficiency tests, thereby confirming their role as an efficient pollinator. In contrast, small-sized visitors such as A. apiformes, although having access to the floral tube, did not contact the anthers and stigma since they have a smaller body size than the floral tube. Hence, the diameter of the tube and body size of the visitors are related to pollen removal and contact with stigma. MurCIA (1990) also observed the relation between the size of visitors and flowers of Ipomoea trichocarpa Ell., in Florida (USA) for the pollination efficiency.

Other pollination studies with species of Ipomoea recognise individuals of Melitoma as very common visitors on these flowers, and these bees were considered oligolectic in pollen collection (WCISLO \& CANE, 1996; SCHLINDWEIN, 1998; MARTINS, 2002). Generally, oligolectic bees visit many flowers from the same species, collecting resources faster than other visitors (WILLMER \& STONE, 2004). SCHLINDWEIN (2004) reports in studies performed in Brazil that oligolectic bees are nearly always efficient pollinators. However, generalist bees were also efficient in plant pollination. In the case of I. bahiensis, the flowers were much visited by the generalist honey bees (A. mellifera). This bee presented behaviour and size compatible with the flowers reproductive system and was the second species in the efficiency tests, contributing to increase the reproductive success of the plant, being considered a potential pollinator.

Association of morphological and behavioural traits of floral visitors is crucial to set apart efficient pollinators from those which are only floral visitors. Hence, the importance of visitor size and tube morphology for pollination in $I$. bahiensis is evident. In this sense, flowers with floral tubes can attract two groups of visitors (bees and butterflies) like observed in this study on I. bahiensis but only medium-sized bees acted as efficient pollinators, although the butterflies were also frequent, they played no role as flower pollinators.

Acknowledgments. We thank Dr Fernando Silveira (UFMG) for the identification of bee species analysed in this study; Dr Marlon Paluch (UFRB/BA) for the identification of Lepidoptera species; Dr Efigênia de Melo (UEFS/BA) for the identification of plant species; Alan Moreira for the field support. We also thank UEFS and CAPES for the financial support for this project development.

\section{REFERENCES}

ANDERSON, B. Johnson, S. D. 2008. The geographical mosaic of coevolution in a plant-pollinator mutualism. Evolution 62:220-225.

Frankie, G. W.; Haber, W. A.; Opler, P. A. \& Bawa, K. S. 1983. Characteristics and organization of the large bee pollination system in the Costa Rican dry forest. In: Jones, C. E. \& Little, R. J. eds. Handbook of experimental pollination biology. New York, Van Nostrand Reinhold, p. 411-447.

Hothorn, T.; Bretz, F. \& Westfall, P. 2008. Simultaneous Inference in General Parametric Models. Biometrical Journal 50:346-363.

KöPPEN W. \& GeIGER, R. 1928. Klimate der Erde. Gotha: Verlag Justus Perthes. Wall-map $150 \mathrm{~cm} \times 200 \mathrm{~cm}$.
Machado, I. C. S. \& SAZima, M. 1987. Estudo comparativo da biologia floral em duas espécies invasoras: Ipomoea heredifolia e I. quamoclit (Convolvulaceae). Revista Brasileira de Biologia 47:425-436.

Maimoni-Rodella, R. C. S. \& Yanagizawa, Y. A. N. 2007. Floral biology and breeding system of three Ipomoea weeds. Planta Daninha 25:35-42.

Marais, D. L. D. \& Rausher, M. D. 2010. Parallel evolution at multiple levels in the origin of hummingbird pollinated flowers in Ipomoea. The Society for the Study of Evolution. Evolution 64(7):2044-2054.

Martins, C. F. 2002. Diversity of the Bee Fauna of the Brazilian Caatinga. In: Kevan, P. \& Imperatriz-Fonseca, V. L. eds. Pollinating Bees The Conservation Link Between Agriculture and Nature. Brasília, Ministério do Meio Ambiente, p. 131-134.

MurCiA, C. 1990. Effect of Floral Morphology and Temperature on Pollen Receipt and Removal in Ipomoea trichocarpa. Ecology 71(3):10981109.

Ne’eman, G.; Jürgens, A.; Newstrom-Lloyd, L.; Potts, S. G. \& Dafni, A. 2010. A framework for comparing pollinator performance: effectiveness and efficiency. Biological Reviews 85:435-451.

Pacheco-Filho, A. J. S.; Westerkamp, C. \& Freitas B. M. 2011. Ipomoea bahiensis pollinators: Bees or butterflies? Flora 206:662- 667.

Parra-Tabla, V. \& Bullock, S. H. 2003. Exploring the limiting causes of fruit production in the tropical tree Ipomoea wolcottiana Rose (Convolvulaceae). Plant Ecology 166:107-115.

PAZ, J. R. L. \& PigOzzo, C. M. 2013. Guilda de visitantes florais de quatro espécies simpátricas de Convolvulaceae: composição e comportamento. Acta Biológica Paranaense 42:7-27.

Paz, J. R. L.; Gimenes, M. \& Pigozzo, C. M. 2013. Three diurnal patterns of anthesis in Ipomoea carnea subsp. fistulosa (Convolvulaceae): Implications for temporal, behavioral and morphological characteristics of pollinators? Flora 208:138-146.

Pick, R. A. \& SCHLIndweIn, C. 2011. Pollen partitioning of three species of Convolvulaceae among oligolectic bees in the Caatinga of Brazil. Plant Systematics and Evolution 293:147-159.

Pinto-Torres, E. \& Koptur, S. 2009. Hanging by a coastal strand: breeding system of a federally endangered morning-glory of the south-eastern Florida coast, Jacquemontia reclinata. Annals of Botany 104:13011311.

R Core Team. 2017. R: A language and environment for statistical computing. R Vienna, Foundation for Statistical Computing. Available at $<$ https://www.R-project.org/>.

RoubiK, D. W. 1989. Ecology and natural history of tropical bees. Cambridge, Cambridge University Press. 514p.

Santana, J. R. F. \& Santos, G. M. M. 1999. Arborização do campus da UEFS: um exemplo a ser seguido ou um grande equívoco? Sitientibus 20:103-107.

SCHLINDWEIN, C. 1998. Frequent oligolecty characterizing a diverse beeplant community in a xerophytic bushland of Sub tropical Brazil. Studies on Neotropical Fauna and Environment 33:46-59.

Schlindwein, C. 2004. Are oligolectic bees always the most effective pollinators? In: Freitas, B. M. \& Pereira, J. O. P. eds. Solitary bees. Conservation, rearing and management for pollination. Fortaleza, Imprensa Universitária, p. 231-240.

Terada, Y.; Taniguchi, A. P; Ruvolo-Takasusuki, M. C. C. \& Toledo, V. A. A. 2005. Floral biology of four Ipomoea (Tubiflorae: Convolvulaceae) species. Acta Scientiarum, Animal Sciences 27(1):137-143.

WCISLO, W. T. \& CANE, J. H. 1996. Floral resource utilization by solitary bees (Hymenoptera: Apoidea) and exploitation of their stored foods by natural enemies. Annual Review of Entomology 41:257-286.

Willmer, P. G. \& Stone, G. N. 2004. Behavioral, ecological, and physiological determinants of the activity patterns of bees. Advances in the Study of Behavior 34:347-466.

Zuur, A. F.; Leno, E. N.; Walker, N.; Saveliev, A. A. \& Smith, G. M. 2009. Mixed effects models and extensions in ecology with R. Berlin, Springer. 574p. 